\title{
The influence of comorbidities on mortality in bronchiectasis: A prospective, observational study
}

\author{
Adam Nowiński ${ }^{A-F}$, Katarzyna Stachyra ${ }^{A-F}$, Maria Szybińska ${ }^{A-F}$, \\ Michał Bednarek ${ }^{A-F}$, Robert Pływaczewski ${ }^{A-F}$, Paweł Śliwiński ${ }^{A-F}$ \\ $2^{\text {nd }}$ Department of Respiratory Medicine, Institute of Tuberculosis and Lung Diseases, Warszawa, Poland \\ A - research concept and design; B - collection and/or assembly of data; C - data analysis and interpretation; \\ $D$ - writing the article; $E$ - critical revision of the article; $F$ - final approval of the article
}

Address for correspondence

Adam Nowiński

E-mail: a.nowinski@igichp.edu.pl

Funding sources

None declared

Conflict of interest

None declared

Received on August 25, 2021

Reviewed on October 18, 2021

Accepted on November 23, 2021

Published online on December 17, 2021

Cite as

Nowiński A, Stachyra K, Szybińska M, Bednarek M,

Pływaczewski R, Śliwiński P. The influence of comorbidities

on mortality in bronchiectasis: A prospective, observational

study. Adv Clin Exp Med. 2021;30(12):1315-1321.

doi:10.17219/acem/144200

DOI

10.17219/acem/144200

Copyright

Copyright by Author(s)

This is an article distributed under the terms of the

Creative Commons Attribution 3.0 Unported (CC BY 3.0)

(https://creativecommons.org/licenses/by/3.0/)

\section{Abstract}

Background. Bronchiectasis is a progressive chronic disease associated with an increased risk of mortality.

Objectives. To identify the prevalence of comorbidities in patients with bronchiectasis and the impact of these comorbidities on mortality.

Materials and methods. A cohort of 93 patients with computed tomography (CT)-confirmed bronchiectasis admitted consecutively to a tertiary teaching hospital was observed over a period of 5 years. All patients were carefully observed for comorbidities and mortality.

Results. A total of 43 men (46.2\%) and 50 women (53.8\%) with a median age of 66.0 years (interquartile range (IQR) 59.7-74.0 years), and a median of 3 comorbidities at baseline (IQR 1-5) were observed. The mortality rate during the observation period was 16\%. The median number of comorbidities was significantly higher in the group of non-survivors (5 (IQR 3-5.75)) compared with survivors (3 (IQR 1-4); $p=0.0100)$. The burden of comorbidities was associated with an increased hazard of death: having 4 or more comorbidities was associated with an increased risk of death compared to patients with 2 or 3 coexisting illnesses (hazard ratio $(\mathrm{HR})=1.35$ (95\% confidence interval $(95 \% \mathrm{Cl})[0.41,4.41]) ; p=0.0494)$. The Bronchiectasis Aetiology Comorbidity Index (BACI) was a significant predictor of death in patients with severe bronchiectasis.

Conclusions. We found a significant number of comorbidities in patients with bronchiectasis. In these patients, the comorbidity burden has an impact on mortality. The BACl is a useful tool for the clinical assessment of patients with severe bronchiectasis.

Key words: survival, bronchiectasis, comorbidities, mortality 


\section{Background}

Bronchiectasis is a progressive chronic disease associated with an increased risk of mortality. In recent years, several prospective studies assessing the survival of patients with non-cystic fibrosis (CF) bronchiectasis have been conducted. A Turkish study found a $16.3 \%$ mortality rate during 4 years of follow-up. ${ }^{1}$ In the UK, the mortality rate was $29.7 \%$ during 13 years of follow-up, ${ }^{2}$ and a singlecenter study in Belgium found a mortality rate of $20.4 \%$ after 5.18 years of follow-up. ${ }^{3}$

Subsequently, multicenter studies assessing factors affecting mortality allowed for the preparation of complex tools that help in estimating the risk of death. The FACED (FEV1, age, Psedomonas aeruginosa colonisation, radiological extension, and dyspnoea) score $^{4}$ and the Bronchiectasis Severity Index $(\mathrm{BSI})^{5}$ were thus generated, and they have proven to be clinically helpful in assessing the individual risk of death. Recently, the attention has also been directed to the impact of another factor that significantly affects the prognosis of bronchiectasis patients: comorbidities. The occurrence of cardiovascular disease (CVD), ${ }^{6}$ infections or kidney diseases, ${ }^{7}$ and rheumatological diseases ${ }^{8}$ increase the mortality of patients with bronchiectasis.

The multiple comorbidities that are frequent in bronchiectasis patients and can negatively affect survival, prompted McDonnell et al. to develop the Bronchiectasis Aetiology Comorbidity Index (BACI), a new tool prepared to assess the individual risk of mortality. ${ }^{9}$

However, studies assessing the impact of comorbidities on the mortality of bronchiectasis patients are still scarce. Further research is needed, particularly regarding the validation of existing clinical prediction scores in independent prospective studies.

\section{Objectives}

In this observational study, our aim was to identify the prevalence of comorbidities in patients with bronchiectasis and the impact of these comorbidities on mortality.

\section{Materials and methods}

This study was performed in the tertiary teaching hospital. We designed an observational, prospective study involving a Polish center specialized in the treatment of patients with non-CF bronchiectasis. During the five-year study (20152019), 100 consecutive patients aged $\geq 18$ years with a confirmed diagnosis of non-CF bronchiectasis were enrolled.

Before being included in the study, all study participants signed a consent to participate in the study. The study protocol was reviewed and approved by the research ethics committee of the Institute of Tuberculosis and Lung Diseases in Warszawa, Poland. All procedures involving human participants and the written consent submitted by participants followed the scientific ethical standards of the 1964 Declaration of Helsinki and its later amendments.

All patients were assessed according to the current guidelines of the British Thoracic Society (BTS) and the European Respiratory Society (ERS). The diagnosis of bronchiectasis was based on high-resolution computed tomography (HRCT) scans performed prior to the study. ${ }^{10}$ Patients with CF were not included. All participants were carefully examined for comorbidities. Comorbidity was defined as a disease coexisting with the primary disease of interest, as suggested by Sin et al. ${ }^{11}$ Diagnoses were made by a group of respiratory and internal medicine specialists and were established following the current relevant international guidelines. Diseases that resolved completely during the hospital stay were excluded from the assessment. The list of diagnoses for each patient, including comorbidities, was recorded in an electronic database.

The diseases were counted and grouped into typical comorbidity groups, as proposed by Charlson et al. investigating comorbidities in respiratory medicine. ${ }^{12}$

The BACI was calculated as proposed by McDonnell et al. ${ }^{9}$ For the assessment of comorbidities, all physicians were free to review the patients' medical files and to order any additional tests, including radiology and biochemistry tests.

\section{Statistical analyses}

Results are expressed as a median quartile range, as numbers, and as relative frequency (n, \%). Dichotomous variables were compared using the $\chi^{2}$ test. The Kolmogorov-Smirnov test was used to check the normality of variable distribution. As the presented data did not meet the assumptions for the parametric tests, the MannWhitney $\mathrm{U}$ test was used to test the differences between the dichotomous groups, and the Kruskal-Wallis test was used to compare more than 2 groups. Survival analysis was performed with the Kaplan-Meier estimate. The log-rank test with post hoc Bonferroni correction was used for comparisons of the survival curves. Results were considered to be statistically significant at $\mathrm{p}<0.05$. The Strengthening The Reporting of OBservational Studies in Epidemiology (STROBE) recommendations for observational studies were followed during protocol preparation. ${ }^{13}$ All statistical calculations were performed with MedCalc software v. 19.1.6 (MedCalc, Ostend, Belgium).

\section{Results}

\section{Characteristics of the group and comorbidities}

Initially, 100 unselected consecutive patients with confirmed non-CF bronchiectasis were enrolled in the study. 
From this group, 7 patients were excluded due to a lack of proper written consent, being lost to follow-up, or due to the withdrawal of consent during the observation period. Mortality was evaluated in the remaining patients at the end of the five-year follow-up period. The final assessment included a group of 93 patients: 43 men (46.2\%) and 50 women $(53.8 \%)$ with a median age of $66.0(59.7-74.0)$ years.

Table 1. Characteristics of the study group. The data are reported as median with interquartile range (IQR) or number with prevalence

\begin{tabular}{|c|c|}
\hline Demographics & Cohort $(n=93)$ \\
\hline Age [years] & $66.0(59.7-74.0)$ \\
\hline Female sex, n (\%) & $50(53.8)$ \\
\hline BMI $\left[\mathrm{kg} / \mathrm{m}^{2}\right]$ & $25.9(21.9-29.6)$ \\
\hline Ex-smokers, n (\%) & $47(50.5)$ \\
\hline Current smokers, n (\%) & $15(16.1)$ \\
\hline Never smokers, n (\%) & $31(33.3)$ \\
\hline \multicolumn{2}{|l|}{ Etiology } \\
\hline ABPA, n (\%) & $1(1.1)$ \\
\hline Alpha1 antitrypsin deficiency, $n(\%)$ & $1(1.1)$ \\
\hline Asthma, n (\%) & $2(2.2)$ \\
\hline COPD, n (\%) & $6(6.5)$ \\
\hline Idiopathic, n (\%) & $56(60.2)$ \\
\hline IgG subclass deficiency, $n(\%)$ & $1(1.1)$ \\
\hline Mounier-Kuhn syndrome, n (\%) & $1(1.1)$ \\
\hline Nontuberculous mycobacteria, n (\%) & $2(2.2)$ \\
\hline Postinfective, n (\%) & $11(11.8)$ \\
\hline Post-tuberculous, n (\%) & $9(9.7)$ \\
\hline Primary ciliary dyskinesia, n (\%) & $1(1.1)$ \\
\hline Yellow nail syndrome, n (\%) & $2(2.2)$ \\
\hline \multicolumn{2}{|c|}{ BSI score risk class } \\
\hline Mild, n (\%) & $28(30.1)$ \\
\hline Moderate, n (\%) & $28(30.1)$ \\
\hline Severe, $n(\%)$ & $37(39.8)$ \\
\hline \multicolumn{2}{|c|}{ Clinical status } \\
\hline Sputum volume $[\mathrm{mL} /$ day $]$ & $10(10-20)$ \\
\hline MRC dyspnea score [points] & $2(1-2)$ \\
\hline $\begin{array}{l}\text { Exacerbations not requiring secondary } \\
\text { care in the previous year, } n\end{array}$ & $1(0-2)$ \\
\hline $\begin{array}{l}\text { At least } 1 \text { hospitalization in the previous } \\
\text { year, } \mathrm{n}(\%)\end{array}$ & $46(49.5)$ \\
\hline \multicolumn{2}{|c|}{ Functional status } \\
\hline $\mathrm{FEV}_{1}, \%$ predicted & $79.8(53.7-98.6)$ \\
\hline \multicolumn{2}{|c|}{ Microbiology } \\
\hline P. aeruginosa infection, $\mathrm{n}(\%)$ & $12(12.9)$ \\
\hline \multicolumn{2}{|c|}{ Comorbidity burden } \\
\hline Number of comorbidities at baseline, $n$ & $3(1-5)$ \\
\hline Number of comorbidities range, $n$ & $0-8$ \\
\hline
\end{tabular}

$\mathrm{BMI}$ - body mass index; COPD - chronic obstructive pulmonary disease; TB - tuberculosis; ABPA - allergic bronchopulmonary aspergillosis; BSI - bronchiectasis severity index; MRC - Medical Research Council; $\mathrm{FEV}_{1}$ - forced expiratory volume in $1 \mathrm{~s}$; P. aeruginosa - Pseudomonas aeruginosa; lgG - immunoglobulin $G$.
Table 2. Most prevalent comorbidities in the study group

\begin{tabular}{|c|c|c|}
\hline Comorbidity & Number of patients & Prevalence (\%) \\
\hline Cardiovascular diseases & 61 & 65.5 \\
\hline COPD & 48 & 51.6 \\
\hline Hypertension & 32 & 34.4 \\
\hline Asthma & 25 & 26.9 \\
\hline Obesity & 22 & 23.6 \\
\hline Coronary heart disease & 18 & 19.4 \\
\hline Diabetes & 16 & 17.2 \\
\hline Cancer/neoplasm & 12 & 12.9 \\
\hline Congestive heart failure & 12 & 12.9 \\
\hline Chronic respiratory failure & 11 & 11.8 \\
\hline Osteoporosis & 9 & 9.7 \\
\hline Tuberculosis in anamnesis & 9 & 9.7 \\
\hline Chronic atrial fibrillation & 8 & 8.6 \\
\hline Pulmonary hypertension & 7 & 7.5 \\
\hline Anxiety/depression & 7 & 7.5 \\
\hline Anemia & 5 & 5.4 \\
\hline Chronic renal disease & 4 & 4.3 \\
\hline Liver cirrhosis & 3 & 3.2 \\
\hline Other arrhythmia & 2 & 2.2 \\
\hline Aortic aneurysm & 1 & 1.1 \\
\hline Sarcoidosis & 1 & 1.1 \\
\hline
\end{tabular}

COPD - chronic obstructive pulmonary disease.

The anthropometric data and comorbidities of the patients are shown in Table 1 and Table 2, respectively.

The group consisted predominantly of middle-aged Caucasians with a median forced expiratory volume in $1 \mathrm{~s}$ $\left(\mathrm{FEV}_{1} \%\right.$ ) predicted of $79.8 \%$ (53.7-98.6\%). The 3 BSI groups were evenly represented: 28 (30.1\%) patients displayed mild bronchiectasis, 28 (30.1\%) had moderate symptoms and 37 patients (39.8\%) had severe symptoms. Bronchiectasis was considered idiopathic in most of the patients $(60.2 \%)$, but it was classified as post-tuberculosis bronchiectasis in $9.7 \%$ of patients. Other, less common causes of bronchiectasis were identified in the remaining patients.

Half of the patients required hospital treatment in the previous year. Twelve patients (12.9\%) were chronically colonized with Pseudomonas aeruginosa. The median number of comorbidities at baseline in the whole group was 3 (interquartile range (IQR) 1-5).

\section{Mortality}

The total observation period in our group was 50 months, but because patients were enrolled consecutively in the study, the median follow-up period for the whole group was 31.0 (IQR 18.5-42.0) months. During the observation period, 15 patients died (16.1\%). The median survival period in non-survivors was 14.0 (IQR 5.2-23.0) months, with a range of 2.0-46.0 months. The median follow-up 


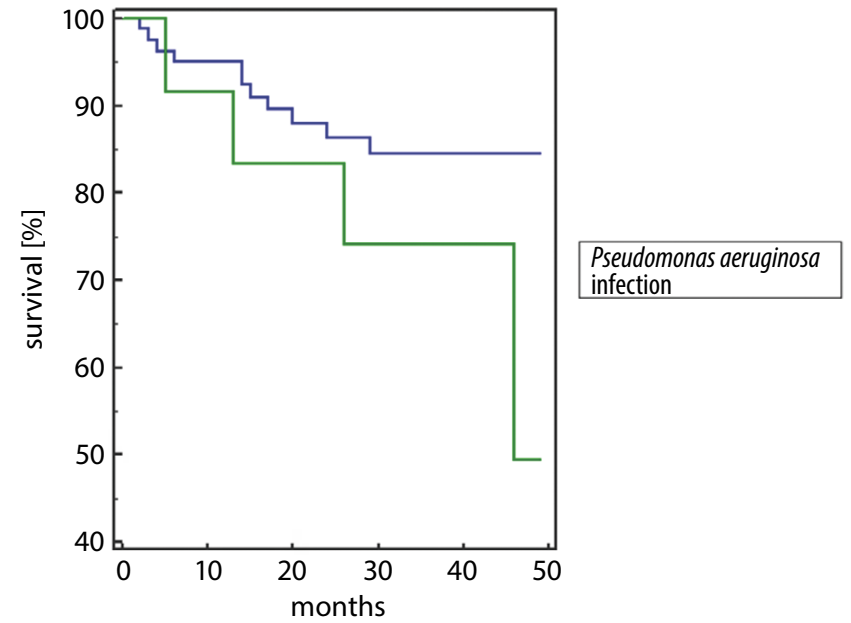

Fig. 1. Kaplan-Meier survival curves demonstrating the survival of patients with non-cystic fibrosis bronchiectasis, with and without Pseudomonas aeruginosa infection

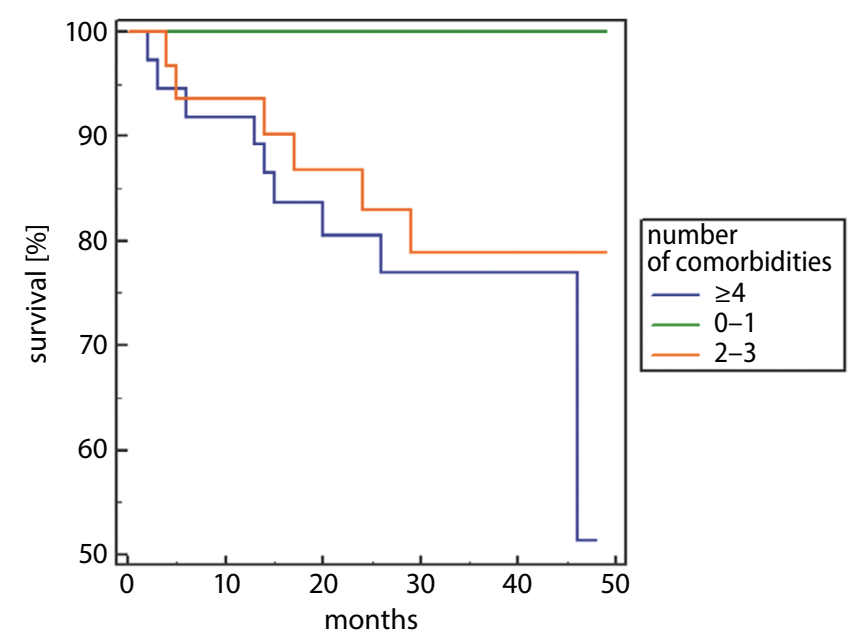

Fig. 2. Kaplan-Meier survival curve showing the survival rates of bronchiectasis patients with different number of comorbidities

for the survivors was 33.0 (IQR 23.0-43.0) months, with a range of 2.0-49.0 months.

The Kaplan-Meier survival curves for the whole group are shown in Fig. 1. The survival curves of patients colonized with $P$. aeruginosa and those not colonized are shown separately because the colonization by $P$. aeruginosa is known to affect the survival.

The number of patients who tested positive for $P$. aeruginosa was small ( $\mathrm{n}=12,12.9 \%)$, and the comparison of survival curves between infected and non-infected patients showed that the difference was not statistically significant $\left(\mathrm{p}=0.1586\right.$, log-rank test, $\left.X^{2}=1.9878\right)$. The hazard ratio (HR) for death in the group with $P$. aeruginosa infection was 2.86 (95\% confidence interval (95\% CI) $[0.66,12.35])$ when compared with the group without $P$. aeruginosa infections.

The median number of comorbidities was significantly higher in the group of non-survivors (5 (IQR 3-5.75)) than in the group of survivors ( $(\mathrm{IQR} 1-4) ; \mathrm{p}=0.0100$, MannWhitney $\mathrm{U}$ test, $\mathrm{U}=341.5)$.
Although the total number of deaths was relatively low, and therefore comparisons are difficult, the burden of comorbidities was associated with an increased hazard of death. Having 4 or more comorbidities was associated with an increased risk of death ( $\mathrm{HR}=1.35$ (95\% CI $[0.41,4.41]))$ compared with patients with 2 or 3 coexisting illnesses ( $p=0.0494$; for HR test, Fig. 2).

\section{$\mathrm{BSI}$ and $\mathrm{BACl}$ scores}

The comparison of the patients' survival curves, grouped according to the BSI score risk classes did not show statistically significant differences between the groups ( $p=0.9682$, log-rank test, $\chi^{2}=0.0645$ ). During the observation period, 15 patients died. In this group of non-survivors, 4 patients had a BSI score in the range of 0-4 points, 4 patients in the range of $5-8$ points and 7 patients had a score over 9 points. The death HR for patients with a BSI score in the range of 0-4 points was similar to that of patients with a BSI score of more than 9 points $(\mathrm{HR}=1.16$ (95\% CI [0.34, 3.91]); $\mathrm{p}=0.9176$; for HR test (Fig. 3)).
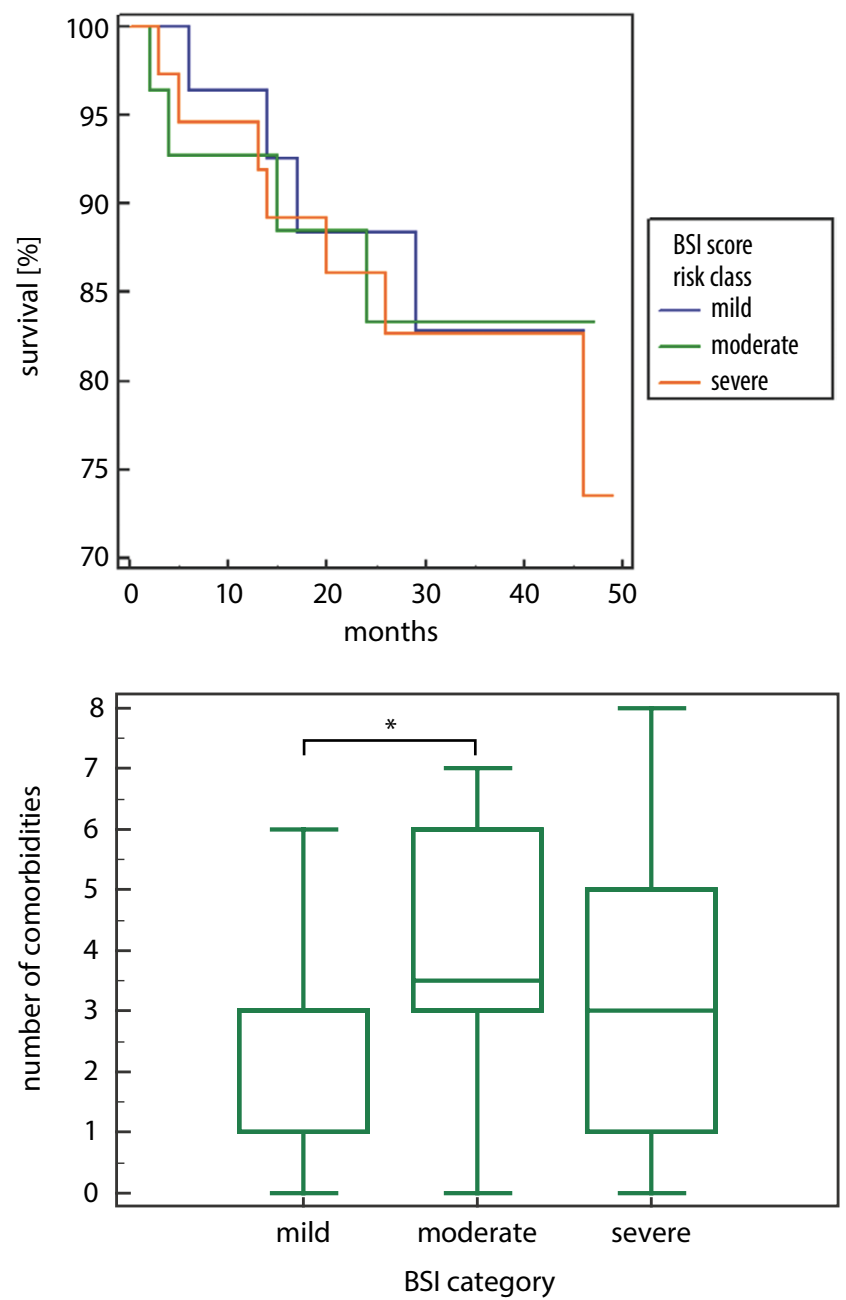

Fig. 3. A. Kaplan-Meier survival curves showing the probability of survival in bronchiectasis patients grouped according to the Bronchiectasis Severity Index (BSI) risk classes; B. The number of comorbidities against the Bronchiectasis Severity Index (BSI) risk classes. The asterisk indicates a statistically significant difference between the groups joined by the line 
A significant, although moderate relationship was observed between the median number of comorbidities and the BSI score. Patients with a BSI score in the "moderate" category had a statistically significantly higher number of comorbidities than patients with a BSI score in the "mild" category ( $\mathrm{p}=0.0367$, Kruskal-Wallis test) (Fig. 3, Supplementary Table 1).

The BACI index classes were analyzed across the survival data. While a high risk BACI score suggested an increased risk of death, this parameter did not reach statistical significance while considering the whole study group $(\mathrm{HR}=1.69$ (95\% CI [0.24, 11.62]); $\mathrm{p}=0.4352$ for HR test). However, when the analysis of the BACI index classes was conducted in the group of patients with the most severe bronchiectasis symptoms (BSI severe class), the BACI was found to be a significant predictor of death $(\mathrm{HR}=7.5(95 \% \mathrm{CI}$ $[1.57,36.29]) ; \mathrm{p}=0.0433$ for HR test) (Fig. 4).

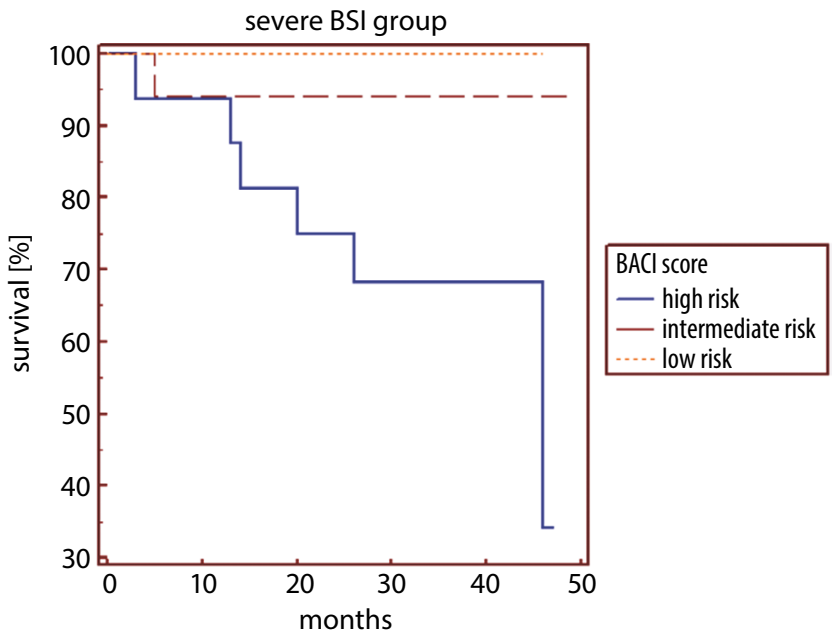

Fig. 4. Kaplan-Meier survival curve showing patient survival against the Bronchiectasis Aetiology Comorbidity Index (BACI) risk classes in the group of patients with severe Bronchiectasis Severity Index (BSI)

\section{Discussion}

The $1^{\text {st }}$ and main finding from this single-center longitudinal prospective study was the impact of the comorbidity burden on mortality in non-CF bronchiectasis. The $2^{\text {nd }}$ finding was the usefulness of the BACI in the prognosis assessment of bronchiectasis patients, which agrees with the previous observations from a multicenter trial. ${ }^{9}$ The $3^{\text {rd }}$ finding was the usefulness of a simple counting of comorbidities in the prediction of the five-year mortality risk in bronchiectasis patients.

\section{Mortality in bronchiectasis}

In our study, we found a $16 \%$ mortality rate over a 50-month follow-up period. These results are consistent with other studies. Onen at al. found that $16.3 \%$ of patients died during an observation period of 44.6 months. The survival rates they observed at $1,2,3$, and 4 years were
97\%, 89\%, 76\%, and 58\%, respectively. ${ }^{1}$ Loebinger et al. reported survival rates of $91 \%$ at 4 years, $83.5 \%$ at 8.8 years and $68.3 \%$ at 12.3 years. $^{2}$

In a multicenter study by Chalmers et al., there were 62 deaths in over 4 years $(10.2 \%)$ in a cohort of 608 patients. In another multicenter study, the overall mortality after $1,2,3$, and 5 years of follow-up was $3.7 \%, 4.8 \%, 8.6 \%$, and $12.4 \%$, respectively. ${ }^{5}$

Our study was a single-center observational study. Therefore, before assessing our results in the context of mortality, we should evaluate whether our study group is similar to other described groups. Our group of patients is comparable to the abovementioned cohorts in terms of age, sex distribution, the etiology of bronchiectasis, and the functional respiratory parameters, such as $\mathrm{FEV}_{1} \%$ predicted. Numerous observational studies have reported that colonization with $P$. aeruginosa significantly affects the prognosis of bronchiectasis patients by increasing the mortality rate. ${ }^{9,14}$ In our study, $12.9 \%$ of patients were colonized with $P$. aeruginosa, which is a slightly smaller percentage compared to other analyzed cohorts. For example, Chalmers et al. and Pasteur et al. reported a 20-40\% prevalence of $P$. aeruginosa in UK cohorts. ${ }^{5,15}$ We observed a possible effect of colonization by $P$. aeruginosa. However, the difference in survival rates between the colonized and non-colonized groups was not statistically significant. One reason for this could be the small size of the study group. Another possible explanation is the low percentage of colonized patients in our group, which could be due to geographical differences in the distribution of the microorganism. ${ }^{16}$

\section{The number and type of comorbidities}

We found a significant number of comorbidities in the study group, with a significantly higher number in the group of nonsurvivors than in the group of survivors. This observation is consistent with the study by McDonnell et al., ${ }^{9}$ who reported that even a simple count of the number of comorbidities has some importance in estimating the risk of death in bronchiectasis patients. Moreover, we found that the risk of death increased significantly with the number of comorbidities: patients with 4 or more comorbidities had a $35 \%$ higher risk of death than patients with 2 or 3 comorbidities.

The number and type of comorbidities in our group of patients is consistent with those described by other research groups. The most frequent comorbidity in our patients was the CVD. It occurred in $65 \%$ of patients, which is similar to the previous observations by other research groups. ${ }^{17,18}$ By analogy with chronic obstructive pulmonary disease (COPD), another important bronchial disease, the chronic inflammation in bronchiectasis could result in an increased risk of the CVD through the "spillover" of inflammatory factors from the bronchial tree into the bloodstream. ${ }^{19}$

In our study, a significant percentage of patients with bronchiectasis were also diagnosed with COPD (51.6\%). 
There is an ongoing discussion regarding the relationship between COPD and bronchiectasis, ${ }^{20,21}$ and statistical analyses sometimes give divergent results. In our study, the reason for the frequent coexistence of bronchiectasis and COPD may be local Polish conditions, which are linked to the socioeconomic factors. In Poland, diagnosing COPD allows doctors to prescribe cheaper drugs with better reimbursement for patients, thereby prompting doctors to diagnose COPD more often in patients with bronchiectasis.

The incidence of other comorbidities does not differ significantly from the observations of other researchers, both in retrospective and prospective studies. ${ }^{5,9}$

\section{Outcome prediction tools - BSI and BACI}

We did not find any statistically significant relationship between the severity of bronchiectasis assessed with the BSI and an increased risk of death. Others have reported the BSI to be a good parameter to estimate the risk of death in bronchiectasis patients, but the analysis of the KaplanMeier curves in our study did not confirm these results. This may be due to the small size of our study group and the relatively low number of deaths we observed. It may also be a confirmation of the important role that comorbidities play in the increasing the risk of death in bronchiectasis patients. This observation seems to be confirmed by the BACI scale analysis.
Despite our small group size, we found that patients with severe bronchiectasis and high BACI classes had an increased risk of death compared to the patients with a severe BSI assessment but a lower number and severity of comorbidities. In our opinion, this confirms the usefulness of the BACI in the clinical assessment of patients with bronchiectasis.

\section{Limitations}

This study was not designed as an epidemiological study. Therefore, the overall results of bronchiectasis mortality in our group should be assessed in the context of the study setting. Nevertheless, bronchiectasis requires a multidimensional assessment; coexisting illnesses should be carefully treated in all affected patients. New tools, such as the BSI, FACED and BACI, may prove useful for the clinical assessment of bronchiectasis patients.

\section{Conclusions}

We found a significant number of comorbidities in patients with bronchiectasis. The comorbidity burden has an impact on mortality in patients with bronchiectasis. The Bronchiectasis Aetiology Comorbidity Index (BACI) is a useful tool for the clinical assessment of patients with severe bronchiectasis.

Supplementary Table 1. Number of comorbidities against severity of bronchiectasis expressed in Bronchiectasis Severity Index (BSI) results (mild, moderate, severe)

\section{A. Kruskal-Wallis test}

\begin{tabular}{|l|c|}
\multicolumn{1}{|c|}{ Data } & Number of comorbidities \\
\hline Factor codes & BSI categories \\
\hline Sample size & 93 \\
\hline
\end{tabular}

\section{B. Descriptive statistics}

\begin{tabular}{|l|c|c|c|c|c|c|}
\multicolumn{1}{|c|}{ BSI category } & $\mathrm{n}$ & Minimum & $25^{\text {th }}$ percentile & Median & $75^{\text {th }}$ percentile & Maximum \\
\hline Mild & 28 & 0.0000 & 1.000 & 3.000 & 3.000 & 6.000 \\
\hline Moderate & 28 & 0.0000 & 3.000 & 3.500 & 6.000 & 7.000 \\
\hline Severe & 37 & 0.0000 & 1.000 & 3.000 & 5.000 & 8.000 \\
\hline
\end{tabular}

\section{Kruskal-Wallis test}

\begin{tabular}{|l|c|}
\hline Test statistic & 6.4395 \\
\hline Corrected for ties & 6.6088 \\
\hline Degrees of freedom (df) & 2 \\
\hline Significance level & $\mathrm{p}=0.036720$ \\
\hline
\end{tabular}

D. Post hoc analysis (Conover)

\begin{tabular}{|l|c|c|c|}
\hline \multicolumn{1}{|c|}{ BSI category } & $n$ & Average rank & $\begin{array}{c}\text { Different }(p<0.05) \\
\text { from factor No. }\end{array}$ \\
\hline Mild & 28 & 37.93 & $(2)$ \\
\hline Moderate & 28 & 56.23 & (1) \\
\hline Severe & 37 & 46.88 & - \\
\hline
\end{tabular}


Supplementary Table 2. Comorbidities summary statistics in the whole group

\section{A. Comorbidities summary}

\begin{tabular}{|l|c|}
\hline \multicolumn{1}{|c|}{ Variable } & Comorbidities, $\mathrm{n}$ \\
\hline Sample size & 93 \\
\hline Lowest value & 0.0000 \\
\hline Highest value & 8.0000 \\
\hline Arithmetic mean & 3.2043 \\
\hline $\begin{array}{l}\text { 95\% confidence interval (95\% Cl) for } \\
\text { the arithmetic mean }\end{array}$ & {$[2.7764,3.6322]$} \\
\hline Median & 3.0000 \\
\hline $95 \%$ Cl for the median & {$[3.0000,3.0000]$} \\
\hline Variance & 4.3165 \\
\hline Standard deviation (SD) & 2.0776 \\
\hline Relative standard deviation & $0.6484(64.84 \%)$ \\
\hline Standard error of the mean (SEM) & 0.2154 \\
\hline Coefficient of skewness & $0.2710(p=0.2685)$ \\
\hline Coefficient of kurtosis & $-0.7375(p=0.0348)$ \\
\hline Kolmogorov-Smirnov test ${ }^{a}$ & $D=0.1521$ \\
for normal distribution & reject normality $(p<0.0001)$ \\
\hline
\end{tabular}

a Lilliefors significance correction.

B. Distribution of the number of comorbidities

\begin{tabular}{|l|c|c|}
\hline Percentiles & $\begin{array}{c}\text { Median number } \\
\text { of comorbidities }\end{array}$ & \begin{tabular}{c} 
95\% confidence interval $(95 \% \mathrm{CI})$ \\
\hline 2.5
\end{tabular} \\
\hline 5 & 0.0000 & - \\
\hline 10 & 0.0000 & {$[0.0000,0.6356]$} \\
\hline 25 & 0.8000 & {$[0.0000,1.0000]$} \\
75 & 1.0000 & {$[1.0000,2.0000]$} \\
\hline 90 & 5.0000 & {$[4.0000,6.0000]$} \\
95 & 6.0000 & {$[6.0000,7.0000]$} \\
\hline 97.5 & 6.8500 & {$[6.0000,8.0000]$} \\
\hline
\end{tabular}

\section{ORCID iDs}

Adam Nowiński (1) https://orcid.org/0000-0002-2910-129X Katarzyna Stachyra (1) https://orcid.org/0000-0003-1530-8502 Maria Szybińska (1) https://orcid.org/0000-0002-5850-8419 Michał Bednarek (1) https://orcid.org/0000-0002-6761-5830 Robert Pływaczewski (1) https://orcid.org/0000-0003-4429-1041 Paweł Śliwiński (i) https://orcid.org/0000-0002-1195-784X

\section{References}

1. Onen ZP, Gulbay BE, Sen E, et al. Analysis of the factors related to mortality in patients with bronchiectasis. Respir Med. 2007;101(7): 1390-1397. doi:10.1016/j.rmed.2007.02.002

2. Loebinger MR, Wells AU, Hansell DM, et al. Mortality in bronchiec tasis: A long-term study assessing the factors influencing survival. Eur Respir J. 2009;34(4):843-849. doi:10.1183/09031936.00003709
3. Goeminne PC, Nawrot TS, Ruttens D, Seys S, Dupont LJ. Mortality in non-cystic fibrosis bronchiectasis: A prospective cohort analysis. Respir Med. 2014;108(2):287-296. doi:10.1016/j.rmed.2013.12.015

4. Martínez-García MA, De Gracia J, Relat MV, et al. Multidimensional approach to non-cystic fibrosis bronchiectasis: The FACED score. Eur Respir J. 2014;43(5):1357-1367. doi:10.1183/09031936.00026313

5. Chalmers JD, Goeminne P, Aliberti S, et al. The bronchiectasis severity index: An international derivation and validation study. Am J Respir Crit Care Med. 2014;189(5):576-585. doi:10.1164/rccm.201309-1575OC

6. Gale NS, Bolton CE, Duckers JM, Enright S, Cockcroft JR, Shale DJ. Systemic comorbidities in bronchiectasis. Chron Respir Dis. 2012;9(4): 231-238. doi:10.1177/1479972312459973

7. Dury S, Colosio C, Etienne I, et al. Bronchiectasis diagnosed after renal transplantation: A retrospective multicenter study. BMC Pulm Med. 2015;15(1):141. doi:10.1186/s12890-015-0133-9

8. Puéchal X, Génin E, Bienvenu T, Le Jeunne C, Dusser DJ. Poor survival in rheumatoid arthritis associated with bronchiectasis: A familybased cohort study. PLoS One. 2014;9(10):e110066. doi:10.1371/journal. pone.0110066

9. McDonnell MJ, Aliberti S, Goeminne PC, et al. Comorbidities and the risk of mortality in patients with bronchiectasis: An international multicentre cohort study. Lancet Respir Med. 2016;4(12):969-979. doi:10.1016/S2213-2600(16)30320-4

10. Pasteur MC, Bilton D, Hill AT; British Thoracic Society Bronchiectasis non-CF Guideline Group. British Thoracic Society guideline for non-CF bronchiectasis. Thorax. 2010;65(Suppl 1):i1-i58. doi:10.1136/ thx.2010.136119

11. Sin DD, Anthonisen NR, Soriano JB, Agusti AG. Mortality in COPD: Role of comorbidities. Eur Respir J. 2006;28(6):1245-1257. doi:10.1183/ 09031936.00133805

12. Charlson ME, Pompei $P$, Ales KL, MacKenzie CR. A new method of classifying prognostic comorbidity in longitudinal studies: Development and validation. J Chronic Dis. 1987;40(5):373-383. doi:10.1016/00219681(87)90171-8

13. von Elm E, Altman DG, Egger M, Pocock SJ, Gøtzsche PC, Vandenbroucke JP. The Strengthening the Reporting of Observational Studies in Epidemiology (STROBE) statement: Guidelines for reporting observational studies. Lancet. 2007;370(9596):1453-1457. doi:10.1016/ S0140-6736(07)61602-X

14. Finch S, McDonnell MJ, Abo-Leyah H, Aliberti S, Chalmers JD. A comprehensive analysis of the impact of Pseudomonas aeruginosa colonization on prognosis in adult bronchiectasis. Ann Am Thorac Soc. 2015;12(11):1602-1611. doi:10.1513/AnnalsATS.201506-3330C

15. Pasteur MC, Helliwell SM, Houghton SJ, et al. An investigation into causative factors in patients with bronchiectasis. Am J Respir Crit Care Med. 2000;162(4 Pt 1):1277-1284. doi:10.1164/ajrccm.162.4.9906120

16. De Soyza A, Perry A, Hall AJ, et al. Molecular epidemiological analysis suggests cross-infection with Pseudomonas aeruginosa is rare in non-cystic fibrosis bronchiectasis. Eur Respir J. 2014;43(3):900903. doi:10.1183/09031936.00167813

17. Huang HY, Chung FT, Lo CY, et al. Etiology and characteristics of patients with bronchiectasis in Taiwan: A cohort study from 2002 to 2016. BMC Pulm Med. 2020;20(1):45. doi:10.1186/s12890-020-1080-7

18. Du Q, Jin J, Liu X, Sun Y. Bronchiectasis as a comorbidity of chronic obstructive pulmonary disease: A systematic review and meta-analysis. PLoS One. 2016;11(3):e0150532. doi:10.1371/journal.pone.0150532

19. Barnes PJ, Celli BR. Systemic manifestations and comorbidities of COPD. Eur Respir J. 2009;33(5):1165-1185. doi:10.1183/09031936.00128008

20. Martinez-Garcia MA, Miravitlles M. Bronchiectasis in COPD patients: More than a comorbidity? Int J Chron Obstruct Pulmon Dis. 2017;12: 1401-1411. doi:10.2147/COPD.S132961

21. Nowiński A, Korzybski D, Bednarek M, Geremek AG, Puścińska $E$, Śliwiński P. Does bronchiectasis affect chronic obstructive pulmonary disease comorbidities? Adv Respir Med. 2019;87(6):214-220. doi:10. 5603/ARM.2019.0059 